\title{
Long-term progressive deterioration of visual function after papilledema improved by embolization of a dural arteriovenous fistula in the sigmoid sinus: a case report
}

\author{
Masahiro Zako ${ }^{1 *}$, Kazuhiro Murata ${ }^{1}$, Takashi Inukai ${ }^{2}$, Muneyoshi Yasuda ${ }^{2}$ and Masayoshi Iwaki ${ }^{1}$
}

\begin{abstract}
Introduction: It is generally believed that people affected by papilledema will not have progressive damage to their eyesight if they receive adequate medical care to treat the underlying cause of the papilledema. We present a case that appears to contradict this widely accepted belief.

Case presentation: A 53-year-old Japanese man with tinnitus visited our hospital. His initial best-corrected visual acuity in either eye was not impaired, although they both exhibited papilledema. Magnetic resonance imaging did not reveal a mass or hemorrhagic lesion in our patient's brain. Nevertheless, his best-corrected visual acuity gradually deteriorated over the following three months. Angiography demonstrated a dural arteriovenous fistula in his sigmoid sinus. After embolization therapy, the papilledema improved in both eyes. However, over the subsequent four years, his best-corrected visual acuity progressively deteriorated due to an unknown cause, despite the successful embolization of the dural arteriovenous fistula.
\end{abstract}

Conclusion: There may be delayed onset of an unknown pathophysiology in the visual system after treatment for the underlying cause of papilledema, implying an uncertain visual prognosis for patients with this condition.

Keywords: Dural arteriovenous fistula, Papilledema, Sigmoid sinus, Visual function

\section{Introduction}

Papilledema, also known as choked disc, is an edema of the optic nerve head that is caused by elevated intracranial pressure $[1,2]$. This condition is usually bilateral and results from a cerebral tumor, cerebral abscess, meningitis, encephalitis, subarachnoid hemorrhage, head injury, hydrocephalus, or many other local or systemic pathological conditions. In the early stages, the patient may have a headache, but visual acuity may not be affected. In advanced stages, the papilledema may progress to an enlargement of the blind spot in visual field measurements, blurred vision, visual obscurations, or even total loss of vision. The timeline of visual impairment associated with papilledema is highly variable; major deficits

\footnotetext{
*Correspondence: zako@aichi-med-u.ac.jp

'Department of Ophthalmology, Aichi Medical University, Nagakute, Aichi 480-1195, Japan

Full list of author information is available at the end of the article
}

can arise within weeks in severe cases, but more typically they arise over several months [3]. The risk of impaired visual acuity increases as the duration of the edema increases [4], although the critical duration has not been determined. However, a person affected by papilledema is generally not expected to have progressive damage to their eyesight if they receive adequate medical care for the underlying cause of the papilledema.

We present the case report of a patient with bilateral papilledema, which was caused by a dural arteriovenous fistula (DAVF) in his sigmoid sinus. DAVFs are abnormal arteriovenous connections within the dura mater that involve a dural sinus and/or cortical veins. The most common location for DAVFs is the transverse or sigmoid sinus [5].

After administering the appropriate transarterial and transvenous embolization therapy, our patient's bilateral papilledema improved considerably. However, his visual 
acuity then progressively deteriorated, with consequent disc paling, although he did not exhibit thinning of the retina. Our experience with this patient suggests that there may be delayed onset of an unknown pathophysiology in the visual system after treatment for the underlying cause of papilledema, implying an uncertain prognosis for patients with this condition.

\section{Case presentation}

A 53-year-old Japanese man presented to our hospital complaining of tinnitus over a period of three weeks. He also noted slightly abnormal "fuzzy" vision in the previous two weeks. An otorhinologist was consulted to rule out Vogt-Koyanagi-Harada disease.

An ocular evaluation revealed a best-corrected visual acuity (BCVA) of 1.2 in his right eye and 1.0 in his left eye. His intraocular pressure was $14 \mathrm{mmHg}$ in his right eye and $16 \mathrm{mmHg}$ in his left eye. The anterior segment was normal in both eyes. However, a fundus evaluation revealed a significant papilledema in each eye (Figure 1).

Brain magnetic resonance imaging (MRI) demonstrated the absence of an intracranial mass or hemorrhagic lesion. Our patient did not experience hypertension or uveitis; at that point, he had experienced no loss of BCVA. We did not measure our patient's intracranial pressure because he did not approve the procedure. Because he did not demand further examination, we held follow-up appointments with our patient every two weeks.

Our patient had been taking aripiprazole for depression for over seven years. He was also diagnosed with mild cognitive impairment, also known as incipient dementia, for which he was not receiving treatment.

Ten weeks after his first visit to our hospital, our patient began to experience sporadic marked blurred vision and transient day blindness. His BCVA had deteriorated moderately to 0.9 in his right eye and 0.8 in his left eye. A neurosurgeon detected a DAVF in his sigmoid sinus on angiography. The fistula was classified as type I, according to Borden classification, and type IIa, according to Cognard classification.

Transarterial and transvenous embolization was successfully performed to treat the causative DAVF. Three weeks after therapy, the papilledema had significantly improved (Figure 1) but the BCVA in our patient's right and left eyes was 0.8 and 0.3 , respectively. His tinnitus disappeared by one week after embolization therapy. The angiography results before and after embolization are presented in Figure 2.

We followed this patient for four years. Regular ocular examinations demonstrated the absence of papilledema

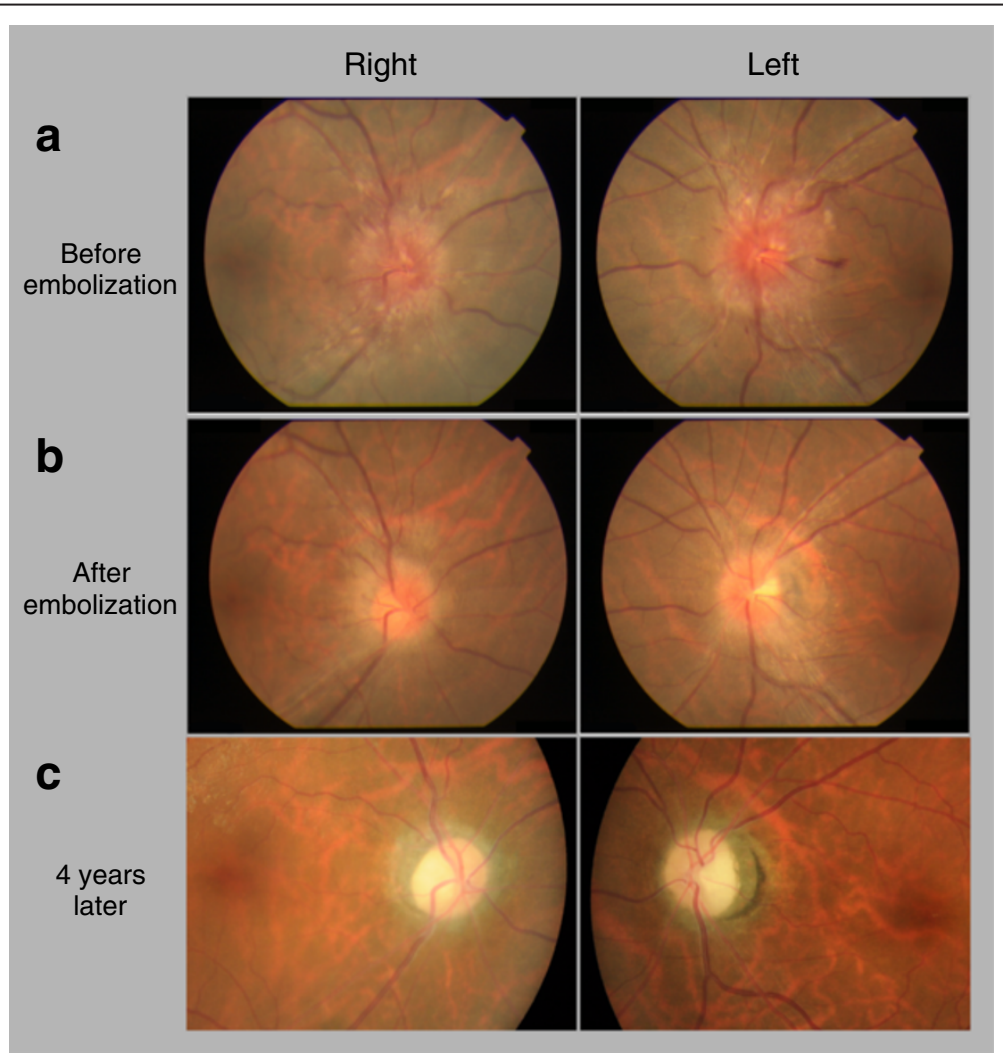

Figure 1 Photographs showing optic discs before and after treatment. (a) Optic disc on the first visit. (b) Optic disc three months after transarterial and transvenous embolization therapy. (c) Optic disc four years after embolization therapy. 


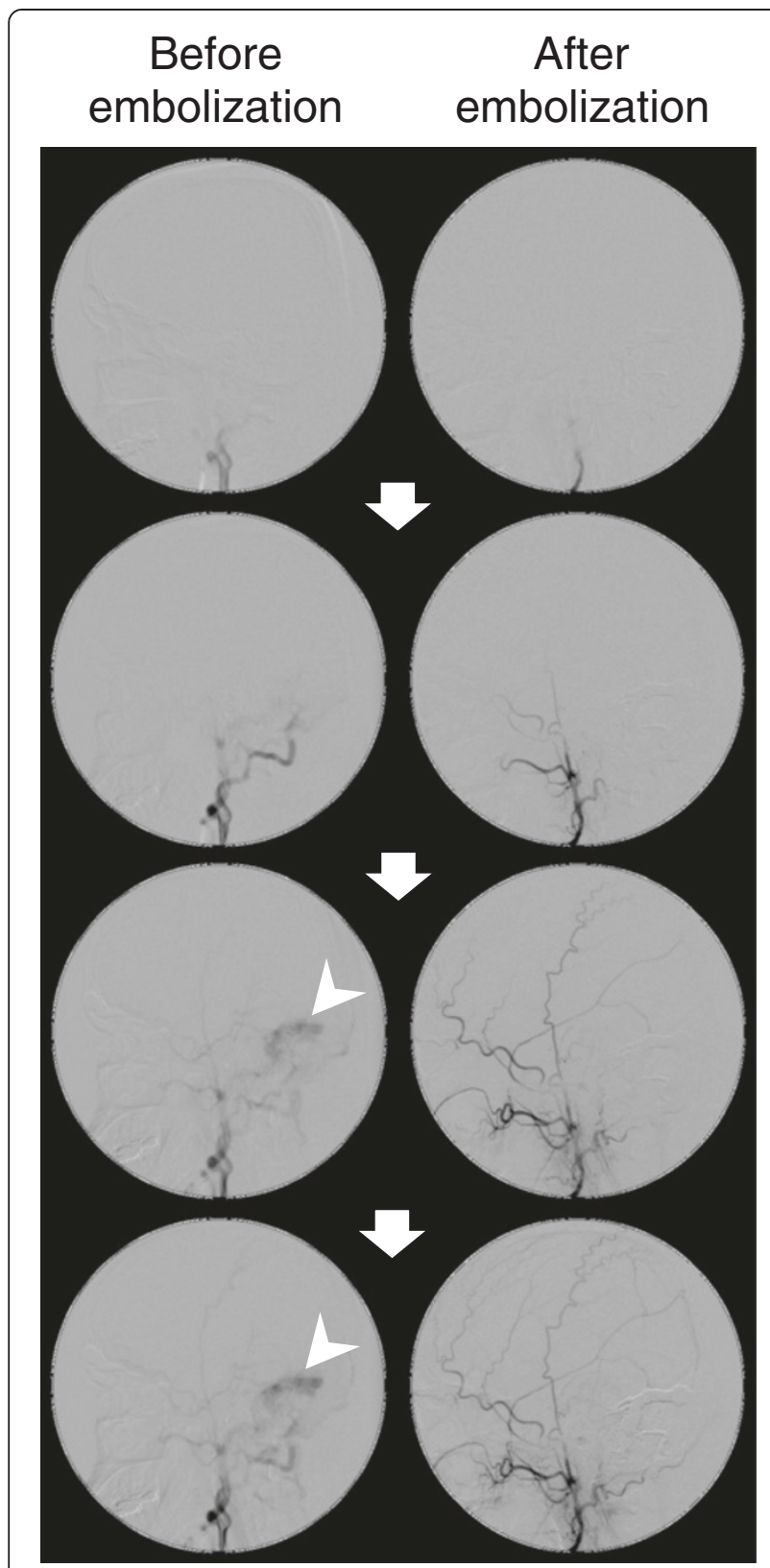

Figure 2 Angiography before and after embolization therapy. Right external carotid angiography (lateral view) demonstrates blood flow into the sigmoid sinus venosus (arrowheads) through the dural arteriovenous fistula. Paired photographs show images of the same phases after embolization therapy. Arrows indicate the time course, from top (early) to bottom (late).

recurrence. However, the patient's BCVA continued to deteriorate progressively (Figure 3), with concurrent complete disc paling (Figure 1) but without thinning of the foveal retina or retina around the disc, as determined by optical coherence tomography (OCT) (Figure 4).

A mild vitreomacular adhesion in his right eye was revealed by OCT with SDOCT RS-3000 (Nidek Co., Ltd,
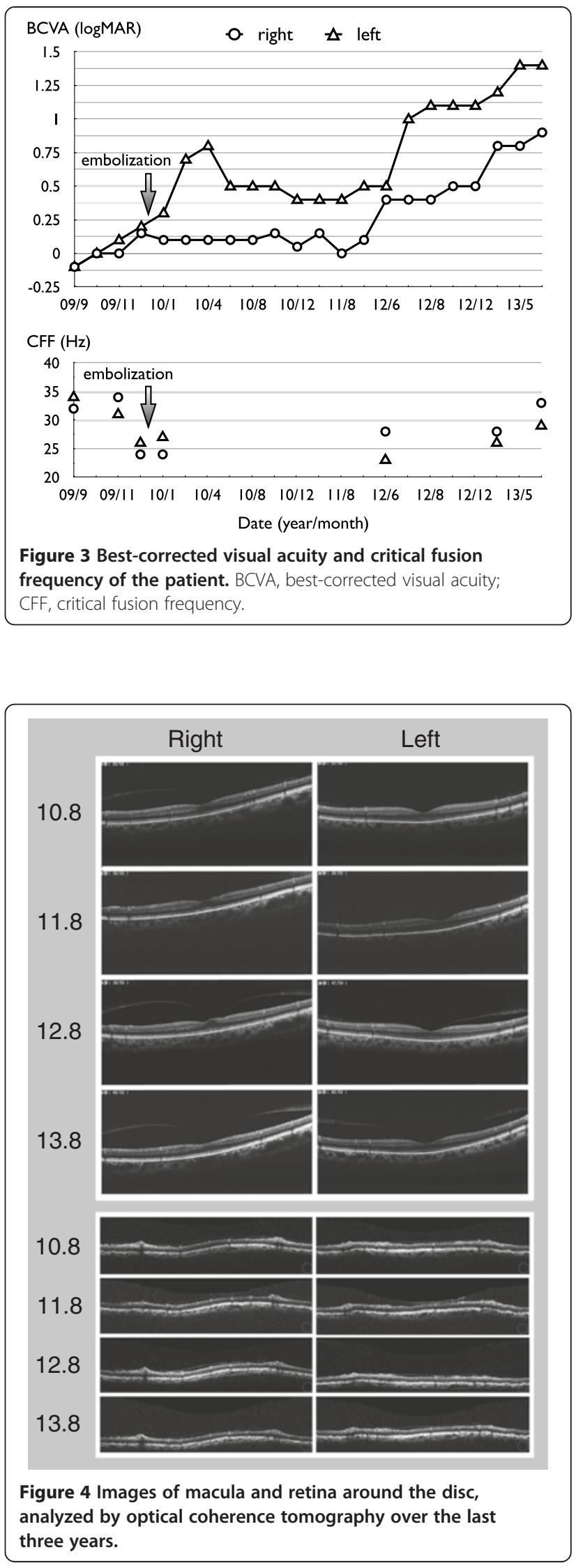
Aichi, Japan) and Nidek Advanced Vision Information System EX version 1.3.0.3 (Nidek Co., Ltd) (Figure 4). Our patient did not notice metamorphopsia, and he did not request pars plana vitrectomy. Goldmann perimetry showed progressive narrowing of the visual field in both eyes after embolization (Figure 5).

Four years after embolization, our patient's BCVA was 0.15 in his right eye and 0.04 in his left eye. His intraocular pressure was within normal range in both eyes at all examinations (data not shown). Our patient's intracranial condition was examined by MRI and magnetic resonance angiogram every six months, but he never had a recurrence of the right DAVF in the sigmoid sinus, nor were there any other abnormal findings.

\section{Discussion}

Patients with papilledema are generally not expected to have progressive damage to their eyesight if they receive adequate medical care to treat the underlying cause of the papilledema. However, the prognosis for visual function can not be determined simply by measuring the extent of damage before treatment. As shown in this case, visual function can continue to deteriorate despite an initial improvement after effective surgery.
To the best of our knowledge, our case report is the first in the literature to describe the progressive deterioration of visual function after appropriate treatment in a patient with DAVF. We speculate that there may have been delayed onset of an unknown pathophysiology in his visual system after treatment for the underlying cause of papilledema, implying an uncertain prognosis with respect to the disease.

It is unclear what caused the initially improved visual function to deteriorate in the few years following treatment. Papilledema can have a number of effects on the visual system, the most severe of which is nerve fiber dysfunction from swelling, with subsequent and progressive loss of the retinal nerve fibers and optic atrophy [6]. Although the definitive pathogenesis of papilledema in response to increased intracranial pressure remains unclear, the prevailing theory is that papilledema is primarily a mechanical nonvascular phenomenon [7,8]. According to this theory, optic disc swelling causes axon compression, which results in hypoxia, ischemia, gliosis, and, finally, optic atrophy due to delayed death or degeneration of neuronal or retinal cells $[6,9]$. Another possibility for the mechanism underlying the delayed neurodegeneration is apoptosis. Optic nerve lamina cribrosa cells that are

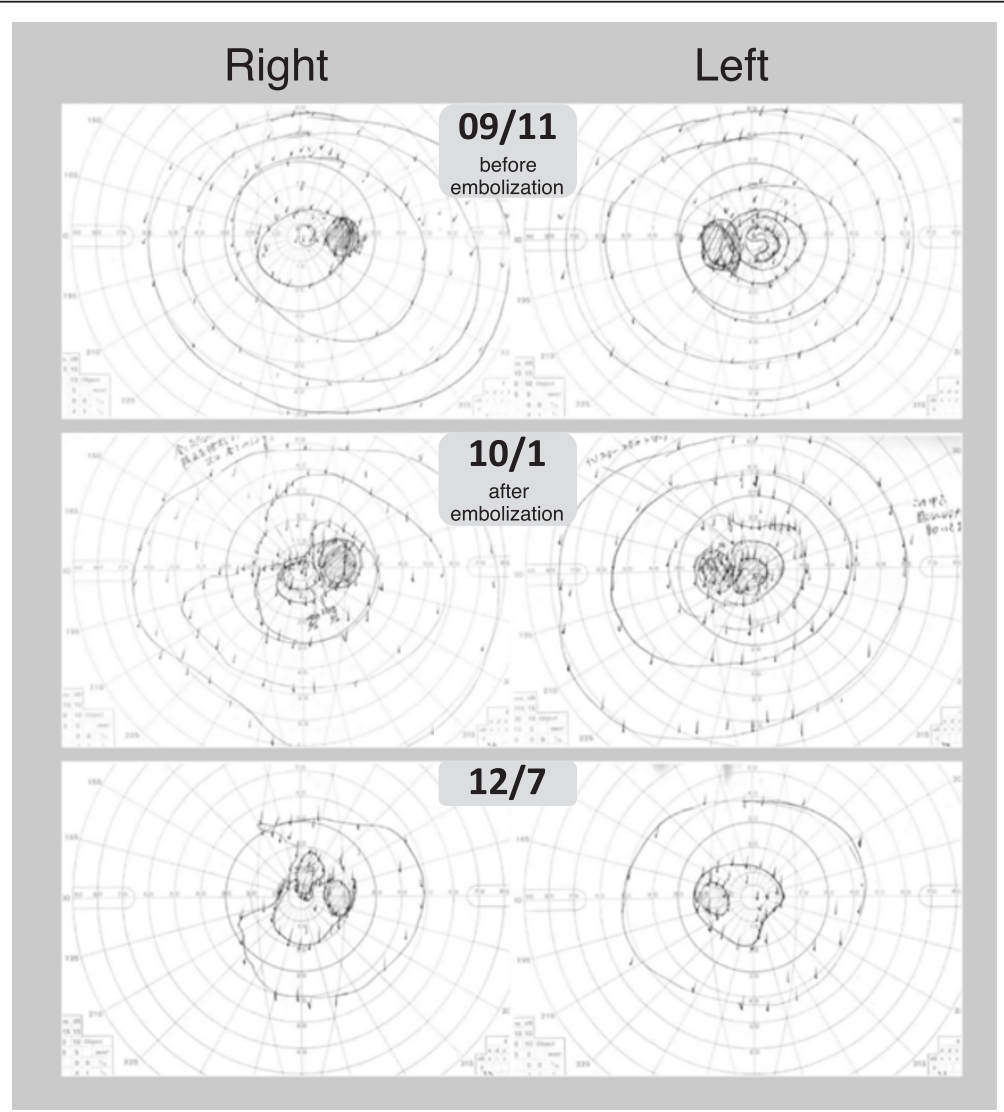

Figure 5 Goldmann kinetic visual field, obtained before and after transarterial and transvenous embolization therapy. 
exposed to hypoxic stress may be involved in apoptosis and neurogenesis [10].

A technique was developed in monkeys to produce papilledema by inflating intracranial balloons [11]. With this method, papilledema did not develop in optic nerves subjected to procedures that resulted in total optic atrophy prior to the elevation of intracranial pressure [12]. Thus, in following up the cause for papilledema in a patient with total optic atrophy, we should use not only fundoscopy but also other appropriate examinations such as intracranial pressure measurement, MRI, and magnetic resonance angiography (MRA).

No remarkable progressive abnormal retinal atrophy was detected by OCT in our case. A central scotoma was detected just after embolization in our patient's left eye, and another scotoma was detected 2.5 years after therapy in his right eye, suggesting the involvement of optic neuropathy. However, his visual field did not indicate a more specific disease or lesion. The precise mechanism of the delayed-onset optic atrophy remains unclear.

A dural arteriovenous malformation is difficult to recognize with brain computed tomography $(\mathrm{CT})$ or MRI, but it can be well documented by MRA and cerebral angiography [13]. In this case, we spent almost three months obtaining an accurate diagnosis, as initial cranial $\mathrm{CT}$ and MRI images did not show any abnormal findings. The DAVF was a cause of the papilledema in this case. The pathogenic theory of papilledema is that it is caused by an increase in cerebral blood volume due to impaired cranial venous outflow, leading to intracranial hypertension [14]. Therefore, if a patient has bilateral papilledema, clinicians should perform MRA or cerebral angiography to rule out intracranial circulatory malformations [15].

If a patient has papilledema plus depression and/or dementia, DAVF should be considered as a cause of these disorders. However, the relationships among DAVF, deteriorated visual function, and symptoms of depression and dementia are not straightforward. DAVF is a cause of depression [16-18], and depression may improve after the DAVF is treated [16]. DAVF is also implicated as a cause of dementia, and dementia may be reversed after treatment for the DAVF [19-25]. Deteriorated visual function itself may elicit depressive symptoms in patients [26-28]. A possible explanation for the lack of significant improvement in our patient's symptoms of depression may be that his visual function continued to deteriorate.

\section{Conclusion}

We have described our experience with a case of bilateral papilledema, which was induced by a DAVF in the sigmoid sinus and subsequently improved following embolization therapy. However, our patient's visual function progressively deteriorated after the successful therapy. This delayed onset of unknown pathophysiology in the visual system after treatment for the underlying cause of papilledema implies an uncertain prognosis for the disease.

\section{Consent}

Written informed consent was obtained from the patient for publication of this case report and any accompanying images. A copy of the written consent is available for review by the Editor-in-Chief of this journal.

\section{Abbreviations}

BCVA: Best-corrected visual acuity; CT: Computed tomography; DAVF: Dural arteriovenous fistula; MRA: Magnetic resonance angiography; MRI: Magnetic resonance imaging; OCT: Optical coherence tomography.

\section{Competing interests}

The authors declare that they have no competing interests.

\section{Authors' contributions}

$\mathrm{KM}, \mathrm{TI}, \mathrm{MY}$, and $\mathrm{Ml}$ analyzed and interpreted the patient data. MZ was a major contributor in writing and revising the manuscript. All authors read and approved the final manuscript.

\section{Acknowledgements}

This study was supported in part by a Strategic Research Foundation Grant for the Aid of Projects in Private Universities, offered by the Ministry of Education, Culture, Sports, Science, and Technology, Japan (MEXT), 2011-2015 (S1101027)

\section{Author details}

'Department of Ophthalmology, Aichi Medical University, Nagakute, Aichi 480-1195, Japan. ²Department of Neurological Surgery, Aichi Medical University, Nagakute, Aichi, Japan.

Received: 30 March 2014 Accepted: 22 September 2014 Published: 28 November 2014

\section{References}

1. Savino PJ, Sergott RC, Moster ML: Papilledema. In The Wills Eye Manual: Office and Emergency Room Diagnosis and Treatment of Eye Disease. 5th edition. Edited by Ehlers JP, Shah CP. Baltimore: Lippincott Williams \& Wilkins; 2008:252-254.

2. Friedman DI: Papilledema. In Walsh \& Hoyt's Clinical Neuro-ophthalmology: The Essentials. 2nd edition. Edited by Miller NR, Newman NJ, Biousse V, Kerrison JB. Baltimore: Lippincott Williams \& Wilkins; 2008:122-145.

3. Acheson JF: Idiopathic intracranial hypertension and visual function. Br Med Bull 2006, 79-80:233-244.

4. Wall M, George D: Idiopathic intracranial hypertension. A prospective study of 50 patients. Brain 1991, 114:155-180.

5. Caragine LP, Halbach W, Dowd CF, Ng PP, Higashida RT: Parallel venous channel as the recipient pouch in transverse/sigmoid sinus dural fistulae. Neurosurgery 2003, 53:1261-1267.

6. Schirmer CM, Hedges TR 3rd: Mechanisms of visual loss in papilledema. Neurosurg Focus 2007, 235:E5

7. Hayreh SS: Optic disc edema in raised intracranial pressure. V. Pathogenesis. Arch Ophthalmol 1977, 95:1553-1565.

8. Wirtschafter JD, Rizzo FJ, Smiley BC: Optic nerve axoplasm and papilledema. Surv Ophthalmol 1975, 20:157-189.

9. Brown GC, Neher JJ: Inflammatory neurodegeneration and mechanisms of microglial killing of neurons. Mol Neurobiol 2010, 41:242-247.

10. Kirwan RP, Felice L, Clark AF, O'Brien CJ, Leonard MO: Hypoxia regulated gene transcription in human optic nerve lamina cribrosa cells in culture. Invest Ophthalmol Vis Sci 2012, 53:2243-2255. 
11. Wirtschafter JD: Optic nerve axons and acquired alterations in the appearance of the optic disc. Trans Am Ophthalmol Soc 1983, 81:1034-1091

12. Hayreh MS, Hayreh SS: Optic disc edema in raised intracranial pressure. I. Evolution and resolution. Arch Ophthalmol 1977, 95:1237-1244.

13. Adelman JU: Headaches and papilledema secondary to dural arteriovenous malformation. Headache 1998, 38:621-623.

14. Cognard C, Casasco A, Toevi M, Houdart E, Chiras J, Merland JJ: Dural arteriovenous fistulas as a cause of intracranial hypertension due to impairment of cranial venous outflow. J Neurol Neurosurg Psychiatry 1998, 65:308-316.

15. Gandhi D, Chen J, Pearl M, Huang J, Gemmete JJ, Kathuria S: Intracranial dural arteriovenous fistulas: classification, imaging findings, and treatment. AJNR Am J Neuroradiol 2012, 33:1007-1013.

16. Nakagawa M, Sugiu K, Tokunaga K, Sakamoto C, Fujiwara K: Improvement of depression after treatment of dural arteriovenous fistula: a case report and a review. Case Rep Psychiatry 2012, 2012:730151.

17. Katz JM, Shetty T, Gobin YP, Segal AZ: Transient aphasia and reversible major depression due to a giant sagittal sinus dural AV fistula. Neurology 2003, 61:557-558.

18. van der Schaaf IC, Brilstra EH, Rinkel GJ, Bossuyt PM, van Gijn J: Quality of life, anxiety, and depression in patients with an untreated intracranial aneurysm or arteriovenous malformation. Stroke 2002, 33:440-443.

19. Henderson JB, Zarghouni M, Hise JH, Opatowsky MJ, Layton KF: Dementia caused by dural arteriovenous fistulas reversed following endovascular therapy. Proc (Bayl Univ Med Cent) 2012, 25:338-340.

20. Mendonça N, Santos G, Duro D, Machado E, Goulão A, Santana I: Multiple dural arteriovenous fistulas presenting as rapidly progressive dementia. Neurologist 2012, 18:130-132

21. Dehdashti AR, Matouk CC, Terbrugge K, Wallace MC, Willinsky RA: Clues to dural arteriovenous fistulas in patients with progressive dementia. Can J Neurol Sci 2010, 37:532-534.

22. Matsumura A, Oda M, Hozuki T, Imai T, Shimohama S: Dural arteriovenous fistula in a case of dementia with bithalamic MR lesions. Neurology 2008, 71:1553

23. Poppe AY, Watson TW, Hudon ME, Puetz V, Wang W: A reversible cause of "vascular dementia". Neurology 2008, 71:226.

24. Kajitani M, Yagura H, Kawahara M, Hirano M, Ueno S, Fujimoto K, Sakaki T, Taoka T, Nakagawa H, Kichikawa K: Treatable fluctuating Parkinsonism and dementia in a patient with a dural arteriovenous fistula. Mov Disord 2007, 22:437-439.

25. Waragai M, Takeuchi H, Fukushima T, Haisa T, Yonemitsu T: MRI and SPECT studies of dural arteriovenous fistulas presenting as pure progressive dementia with leukoencephalopathy: a cause of treatable dementia. Eur J Neurol 2006, 13:754-759.

26. Carrière I, Delcourt C, Daien V, Pérès $K$, Féart C, Berr C, Ancelin ML, Ritchie $K$ : A prospective study of the bi-directional association between vision loss and depression in the elderly. J Affect Disord 2013, 151:164-170.

27. Morse AR: Vision function, functional vision, and depression. JAMA Ophthalmol 2013, 131:667-668.

28. Zhang X, Bullard KM, Cotch MF, Wilson MR, Rovner BW, McGwin G Jr, Owsley C, Barker L, Crews JE, Saaddine JB: Association between depression and functional vision loss in persons 20 years of age or older in the United States, NHANES 2005-2008. JAMA Ophthalmol 2013, 131:573-581.

doi:10.1186/1752-1947-8-392

Cite this article as: Zako et al.: Long-term progressive deterioration of visual function after papilledema improved by embolization of a dural arteriovenous fistula in the sigmoid sinus: a case report. Journal of Medical Case Reports 2014 8:392.

\section{Submit your next manuscript to BioMed Central and take full advantage of:}

- Convenient online submission

- Thorough peer review

- No space constraints or color figure charges

- Immediate publication on acceptance

- Inclusion in PubMed, CAS, Scopus and Google Scholar

- Research which is freely available for redistribution

Submit your manuscript at www.biomedcentral.com/submit
Biomed Central 